\title{
Mechanochemical Synthesis of Fluorapatite-Zinc Oxide (FAp-ZnO) Composite Nanopowders
}

\author{
Bahman Nasiri-Tabrizi and Abbas Fahami \\ Materials Engineering Department, Najafabad Branch, Islamic Azad University, P.O. Box 8514143131, Najafabad, Isfahan, Iran \\ Correspondence should be addressed to Bahman Nasiri-Tabrizi, bahman_nasiri@hotmail.com
}

Received 20 May 2012; Accepted 10 July 2012

Academic Editors: H. Maiwa, C.-F. Yang, and K. Zupan

Copyright ( $) 2012$ B. Nasiri-Tabrizi and A. Fahami. This is an open access article distributed under the Creative Commons Attribution License, which permits unrestricted use, distribution, and reproduction in any medium, provided the original work is properly cited.

\begin{abstract}
Fluorapatite-zinc oxide (FAp-ZnO) composite nanopowders were successfully prepared via mechanochemical process. Characterization of the products was carried out by X-ray diffraction (XRD), Fourier transform infrared spectroscopy (FT-IR) analysis, energy dispersive X-ray spectroscopy (EDX), and field-emission scanning electron microscopy (FE-SEM) techniques. Results revealed that in the absence of $\mathrm{ZnO}$ which produced by hydrothermal method, the single-phase FAp had high-crystalline structure with appropriate morphological features. Furthermore, after $5 \mathrm{~h}$ of milling in the presence of $5 \mathrm{wt} . \% \mathrm{ZnO}, \mathrm{FAp}-5 \mathrm{wt} . \% \mathrm{ZnO}$, composite nanopowders with no impurity phase was obtained. Structural studies illustrated that the milling up to $5 \mathrm{~h}$ was not accompanied by a remarkable change in the structural features. Moreover, the gained composite powders presented an average crystallite size of about $40 \mathrm{~nm}$ for FAp. The FE-SEM observations indicated that the experimental outcome had a cluster-like structure which consisted of several small particles. Finally, results propose a new approach to prepare commercial amounts of novel FAp-based composite nanopowders with high quality and suitable structural and morphological features.
\end{abstract}

\section{Introduction}

Bioceramics and their composites are potential group of materials for medical applications, particularly for implants in orthopaedics, maxillofacial surgery, and dental implants [1]. In the recent years, fluoridated hydroxyapatite [fluorhydroxyapatite; FHAp, $\mathrm{Ca}_{10}\left(\mathrm{PO}_{4}\right)_{6}(\mathrm{OH})_{2-2 x} \mathrm{~F}_{2 x} /$ fluorapatite; FAp, $\left.\mathrm{Ca}_{10}\left(\mathrm{PO}_{4}\right)_{6} \mathrm{~F}_{2}\right]$ has attracted much attention as a promising material to replace hydroxyapatite (HAp, $\left.\mathrm{Ca}_{10}\left(\mathrm{PO}_{4}\right)_{6}(\mathrm{OH})_{2}\right)$ in biomedical applications $[2,3]$. It is found that the incorporation of fluoride ions into the HAp structure considerably increases the resistance of HAp to biodegradation and thermal decomposition [4]. In addition, fluoridated hydroxyapatite could provide better protein adsorption [5] and comparable or better cell attachment than HAp [6]. This substitution also has positive effects on proliferation, morphology, and differentiation of osteoblastic-like cells and promotes the bioactivity [4].

Due to the remarkable interest related to the specific properties of the calcium phosphate-based composites [713], recent studies were focused mostly on the synthesis and characterization of HAp- and FHAp-based nanocomposites with appropriate structural features as well as mechanical properties. However, an ideal reinforcing material for calcium phosphate-based composites has not yet been found and control over nanocomposite characteristics is a challenging task. In spite of a large number of studies on the synthesis of HAp- and FHAp-based composites, methodical investigations were not performed on the preparation of FAp-ZnO composite nanopowders. Therefore, preparation and characterization of FAp- $\mathrm{ZnO}$ composite nanopowders as a novel bioceramic provided the main goal for current research. To date, several approaches, including wet chemical methods [14, 15], hydrothermal processes [16], solidstate reaction [17], and sol-gel method [18], have been developed for the synthesis of nanobioceramics. Among them, mechanochemical process has been extended for the production of a wide range of advanced materials $[19,20]$. The prominent features of this technique are that melting is not essential and that the products have nanostructural characteristics $[17,19,20]$.

In this research, we investigate the possibility of using mechanochemical process to synthesis of FAp- $\mathrm{ZnO}$ composite nanopowders. According to the literature [21], $\mathrm{ZnO}$ 
is very popular in the daily dental practice, because it is the main substitute of some polycarboxylates, in temporary dental cement powders, or in the formula of dental impression materials. In vitro studies have shown that $\mathrm{Zn}$ has direct, specific proliferative effect on osteoblastic cells and a potent and selective inhibitory effect on osteoclastic bone resorption. In addition, a recent report has also exhibited a clinical relationship between osteoporosis and $\mathrm{Zn}$ deficiency in elderly subjects [22]. Thus, we present for the first time an experimental result of FAp- $\mathrm{ZnO}$ composite nanopowders via mechanochemical process. Moreover, structural features (crystallite size, lattice strain, and crystallinity) and morphological characteristics (particle size and shape, particle distribution, and agglomeration) of the composite nanopowders were investigated by using XRD, FT-IR, EDX, and FE-SEM techniques.

\section{Materials and Methods}

2.1. Preparation of $\mathrm{ZnO}$ Powder. All chemicals were of analytical grade and were used without further purification. In a typical process, the precursor solutions were prepared by mixing $\mathrm{Zn}\left(\mathrm{NO}_{3}\right)_{2} \cdot 6 \mathrm{H}_{2} \mathrm{O}(0.05 \mathrm{M})$ with methenamine $\left(\left(\mathrm{CH}_{2}\right)_{6} \mathrm{~N}_{4}, 0.1 \mathrm{M}\right)$ while keeping their volume ratio at $1: 1$. Before being transferred into a Teflon container with about $500 \mathrm{~mL}$ capacity, the mixed solution was sonicated for about 30 min with a rotational speed of $1000 \mathrm{rpm}$. Afterward, $400 \mathrm{~mL}$ of clear precursor solution was transferred into a Teflon container and was sealed in an autoclave, and then heated at $95^{\circ} \mathrm{C}$ for $2 \mathrm{~h}$. Finally, the products were washed three times with distilled water and ethanol, and then dried at room temperature.

2.2. FAp-ZnO Composite Nanopowders Preparation. Commercially available calcium oxide ( $\mathrm{CaO}$, Merck), phosphorous pentoxide $\left(\mathrm{P}_{2} \mathrm{O}_{5}\right.$, Merck), and calcium fluoride $\left(\mathrm{CaF}_{2}\right.$, Merck) were used as starting reagents. The mechanochemical process was carried out in a high-energy planetary ball mill at room temperature under ambient air atmosphere without using any process control agent (PCA). Millings were performed in the sealed Polyamide- 6 vials (vol. $125 \mathrm{~mL}$ ) using Zirconia balls (20 $\mathrm{mm}$ in diameter) with a rotational speed of $600 \mathrm{rpm}$. The weight ratio of ball-to-powder in all samples was $20: 1$. In order to avoid excessive temperature rise within the grinding vial, $45 \mathrm{~min}$ ball milling duration was followed by an interval of $15 \mathrm{~min}$. The objectives of milling were two: to demonstrate synthesis of nanocrystalline FAp, and to produce the homogeneous FAp- $\mathrm{ZnO}$ composite nanopowders (reaction 1).

$$
9 \mathrm{CaO}+3 \mathrm{P}_{2} \mathrm{O}_{5}+\mathrm{CaF}_{2}+\mathrm{ZnO} \longrightarrow \mathrm{Ca}_{10}\left(\mathrm{PO}_{4}\right) 6 \mathrm{~F}_{2}+\mathrm{ZnO}
$$

For the first aim, we utilized the mechanochemical process; the details of this method were explained in our previous work [23]; in summary, the powder mixture were ground on a high-energy planetary mill and were milled for $5 \mathrm{~h}$. For the second aim, distinct amount of $\mathrm{ZnO}$ powder (5 wt.\%) mixed with calcium oxide, phosphorous pentoxide, and calcium fluoride powder blend (reaction 1), and then were milled in planetary ball mill for $5 \mathrm{~h}$.

The powder X-ray diffraction measurements were carried out by a Philips X-ray diffractometer (XRD) with $\mathrm{Cu}-K_{\alpha}$ radiation. Structural features of the powder samples were determined by using "PANalytical X'Pert HighScore" software from the XRD data. The obtained experimental patterns were compared to standards compiled by the Joint Committee on Powder Diffraction and Standards (JCPDS), which involved card no. 15-0876 for FAp, and no. 0361451 for $\mathrm{ZnO}$. Crystallite size and lattice strain of the composite nanopowders were determined by using the XRD data according to the following equations [19]:

$$
\begin{gathered}
D=\frac{K \lambda}{\left(b_{\mathrm{obs}}-b_{\mathrm{std}}\right)(b \cos \theta)}, \\
E^{2}=\frac{\left(b_{\mathrm{obs}}{ }^{2}-b_{\mathrm{std}}{ }^{2}\right)}{(4 \tan \theta)^{2}},
\end{gathered}
$$

where $b$ (in radians) is the structural broadening, which is the difference in integral profile width between a standard, and the unknown sample and $K, \lambda, D, E$, and $\theta$ are the shape coefficient (value between 0.9 and 1.0), the wavelength of the X-ray used $(0.154056 \mathrm{~nm})$, crystallite size, lattice strain, and the Bragg angle $\left({ }^{\circ}\right)$, respectively. The crystallite size and lattice strain determination of the samples was repeated two times for two groups of peaks; one group was ( $\left.\begin{array}{lll}0 & 0 & 2\end{array}\right),(2$

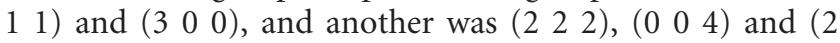
$13)$ miller's planes family; their average being reported as crystallite size and lattice strain.

On the other hand, the relationship between lattice spacing $(d)$ and lattice parameters $(a, b$, and $c)$ of the hexagonal structures (FAp and the FAp in the composite) was expressed as [24]

$$
\frac{1}{d^{2}}=\frac{4}{3} \frac{h^{2}+h k+k^{2}}{a^{2}}+\frac{l^{2}}{c^{2}}
$$

where $h, k, l$ are the Miller indices of the reflection planes. The $\left(\begin{array}{lll}0 & 0 & 2\end{array}\right)$ and $\left(\begin{array}{lll}3 & 0 & 0\end{array}\right)$ reflections were chosen for the lattice parameters calculation.

The change of the lattice parameter of $\mathrm{ZnO}$ nanopowder was calculated using the following equation [25]

$$
\frac{1}{d_{101}^{2}}=\frac{4}{3}\left(\frac{1}{a^{2}}\right)+\frac{1}{c^{2}}
$$

where $d$ is the interplanar distance, $a$ and $c$ are the lattice parameters (being hexagonal structure, $c / a=\sqrt{8 / 3}$ ).

Meanwhile, volume $V$ of the hexagonal unit cell was determined by the following formula [9]:

$$
V=2.589 a^{2} c .
$$

In addition, the crystallinity of FAp and FAp in the composite was determined from the XRD data using the following equation [26]:

$$
X c=\left(\frac{K}{B_{h k l}}\right)^{3}
$$


where $X c, K$, and $B$ are crystallinity, a constant found equal to 0.24 , and FWHM $\left(^{\circ}\right)$ of selected reflection peaks, respectively.

Fourier transform infrared (FT-IR) spectra were recorded using a JASCO (680 Plus) spectrometer in the range of 4000-400 $\mathrm{cm}^{-1}$ using $\mathrm{KBr}$ pellets. Energy dispersive $\mathrm{X}$-ray spectroscopy (EDX) was used for semiquantitative examination of the samples. The size and morphology of fine powders and agglomerates were observed on a field emission scanning electron microscope (FE-SEM Hitachi S1831) that operated at the acceleration voltage of $15 \mathrm{kV}$. Prior to FESEM analysis, the milled powders were suspended in ethanol and dispersed ultrasonically for $3 \mathrm{~min}$. Subsequently, the powder samples were coated with gold for more electronic conduction.

\section{Results and Discussion}

Figure 1(a) shows the XRD patterns for the prepared $\mathrm{ZnO}$ powder. For comparison, the XRD pattern for the standard sample (JCPDS\#036-1451) is also shown in the same figure (Figure 1(b)). The XRD patterns show that the produced sample was high purity polycrystalline $\mathrm{ZnO}$ which had hexagonal wurtzite structure (space group $\mathrm{P} 63 \mathrm{mc}$ ) with lattice parameters, $a$ and $c$, of 3.241 and $5.293 \AA$, respectively. In addition, comparative graph (Figure $1(\mathrm{c})$ ) reveals that the experimental outcome was single-phase $\mathrm{ZnO}$ with complete agreement with the standard sample (JCPDS\#036-1451). Figures 1(d) and 1(e) present the typical morphology of the $\mathrm{ZnO}$ powder. From the FE-SEM observations, it is clear that rods with closed-end and regular hexagonal sections were the dominant morphology. The detailed morphology of the $\mathrm{ZnO}$ powder can be seen under higher magnification in Figure 1(e). The rod-like particles have a diameter of about $200 \mathrm{~nm}-1.5 \mu \mathrm{m}$ and a length of about $1-3 \mu \mathrm{m}$.

Figure 2(a) shows the XRD profile of $\mathrm{CaO}, \mathrm{P}_{2} \mathrm{O}_{5}$, and $\mathrm{CaF}_{2}$ powder mixture in the absence of $\mathrm{ZnO}$ powder after mechanical activation for $5 \mathrm{~h}$. For accurate assessment, the XRD pattern of the standard sample (JCPDS\#15-0876) is presented in the same figure (Figure 2(b)). Due to very high hydrophilicity of $\mathrm{P}_{2} \mathrm{O}_{5}$, phosphoric acid was formed immediately upon addition of $\mathrm{P}_{2} \mathrm{O}_{5}$ to the reaction mixture; thus, characteristic peaks of $\mathrm{P}_{2} \mathrm{O}_{5}$ could not be observed in XRD profile. According to XRD pattern, the product of mechanochemical process was nanocrystalline single phase FAp. FT-IR spectrum of $\mathrm{CaO}, \mathrm{P}_{2} \mathrm{O}_{5}$, and $\mathrm{CaF}_{2}$ powder mixture after $5 \mathrm{~h}$ of milling is shown in Figure 2(c). This spectrum confirms the presence of functional groups that determine the composition of the product and the changes happened during the mechanochemical process. In the FT-IR spectrum, two bands relating to the vibration of the adsorbed water in the apatite structure were detected [3]. A doublet appears at 1428 and $1455 \mathrm{~cm}^{-1}$ corresponding to $\nu_{3}$ and a weak band at $864 \mathrm{~cm}^{-1}$ corresponding to $\nu_{2}$ vibration mode of the carbonated groups. These peaks demonstrate that FAp contained some $\mathrm{CO}_{3}{ }^{2-}$ groups in $\mathrm{PO}_{4}{ }^{3-}$ sites of apatite lattice (B-type substitution) [27]. It has been reported that this kind of apatite is more similar to biological apatite and could be more suitable for bone replacement materials [3]. The characteristic peaks of the phosphate group, which had four distinct asymmetrical stretching vibration modes, namely, $\nu_{1}$ (965 $\left.\mathrm{cm}^{-1}\right), \nu_{2}\left(473 \mathrm{~cm}^{-1}\right), \nu_{3}\left(1094\right.$ and $\left.1049 \mathrm{~cm}^{-1}\right)$, and $\nu_{4}\left(603\right.$ and $\left.575 \mathrm{~cm}^{-1}\right)$ appeared in the broad spectrum. In this sample, the band at $965 \mathrm{~cm}^{-1}$ corresponding to the $\nu_{1}$ vibration of the $\mathrm{PO}_{4}{ }^{3-}$ group appears as a result of the $\mathrm{HPO}_{4}{ }^{2-}$ group depredation [28]. Based on FT-IR spectrum, the band at $727 \mathrm{~cm}^{-1}$ confirmed the formation of FAp with high purity. Figure 2(d) shows the morphology and particle size distribution of the nanocrystalline FAp produced after $5 \mathrm{~h}$ of milling. From the FE-SEM micrograph, it is clear that the powders after $5 \mathrm{~h}$ of milling displayed a clusterlike structure which consisted of several small particles with the average size of about $55 \mathrm{~nm}$. In the field of science and technology of particles, agglomerate size is one of the key factors that influence the densification behaviors of nanoparticles. Large particle size along with hard agglomerates shows lower densification in calcium phosphate ceramics due to the formation of large interagglomerate/intraagglomerate pores [29]. The large interagglomerate/intraagglomerate pores increase the diffusion distance, resulting in lowering the densification rate. To compensate for this, higher sintering temperature becomes necessary. However, higher sintering temperature leads to enhanced grain growth, which changes the morphological features of composite nanopowders [30]. Figure 2(e) shows the schematic picture of the morphological features for single phase FAp nanopowders after $5 \mathrm{~h}$ of milling. This figure demonstrates the morphological features of the nanopowders such as particles shape, agglomerates, and interagglomerate/intraagglomerate pores. According to Figures 2(d) and 2(e), the intraagglomerate pore sizes were much smaller than the interagglomerate pore sizes; thus, during the annealing process, the smaller intraagglomerate pores may be disappeared at a much faster rate than the larger interagglomerate pores due to higher driving force for annihilation. Figure 2(f) shows the EDX spectra of the nanocrystalline FAp after $5 \mathrm{~h}$ of milling. This figure verifies the existence of $\mathrm{Ca}, \mathrm{P}, \mathrm{O}$, and $\mathrm{F}$ inside the particles. Also, a very homogeneous distribution of components was formed during mechanochemical process. Based on the EDX point chemical analysis, no chemically stable contaminants were detected due to the excessive adhesion of powders to the milling media. It should be mentioned that the use of polymeric vial have been proposed in the authors' experiments not only to annihilate contamination problem, but also to achieve modified morphologies with high biomedical performance [23, 31-33].

Figure 3(a) shows the XRD profile of $\mathrm{CaO}, \mathrm{P}_{2} \mathrm{O}_{5}$, and $\mathrm{CaF}_{2}$ powder mixture in the presence of $5 \mathrm{wt} . \% \mathrm{ZnO}$ after $5 \mathrm{~h}$ of milling. Furthermore, to precise phase evaluation, the XRD patterns of the standard FAp (JCPDS\#15-0876) and $\mathrm{ZnO}$ (JCPDS\#036-1451) presented in the same figures (Figures 3(b) and 3(c)). As shown in Figures 3(a)-3(c), after $5 \mathrm{~h}$ of milling the phase compositions were FAp JCPDS\#150876) and $\mathrm{ZnO}$ (JCPDS\#036-1451) without any extra phases. This suggests that the product of mechanical activation is FAp- 5 wt.\% $\mathrm{ZnO}$ composite and no interfacial reactions have not happened during one-step mechanochemical 


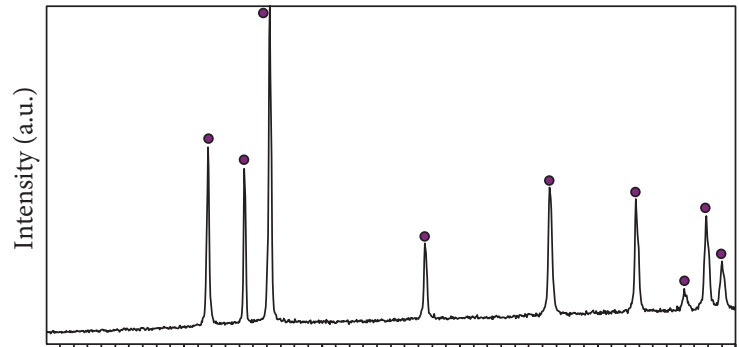

- $\mathrm{ZnO}$

(a)

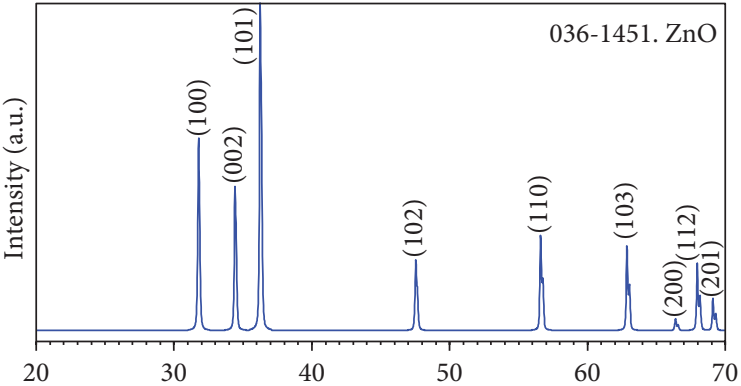

(b)

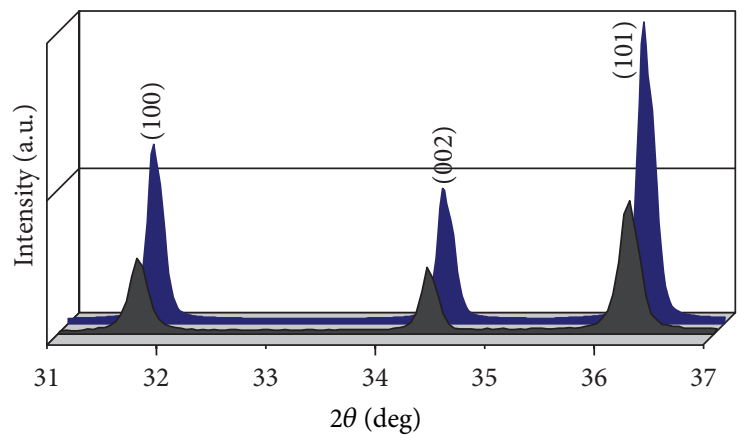

- $\mathrm{ZnO}$

- 036-1451 ZnO

(c)

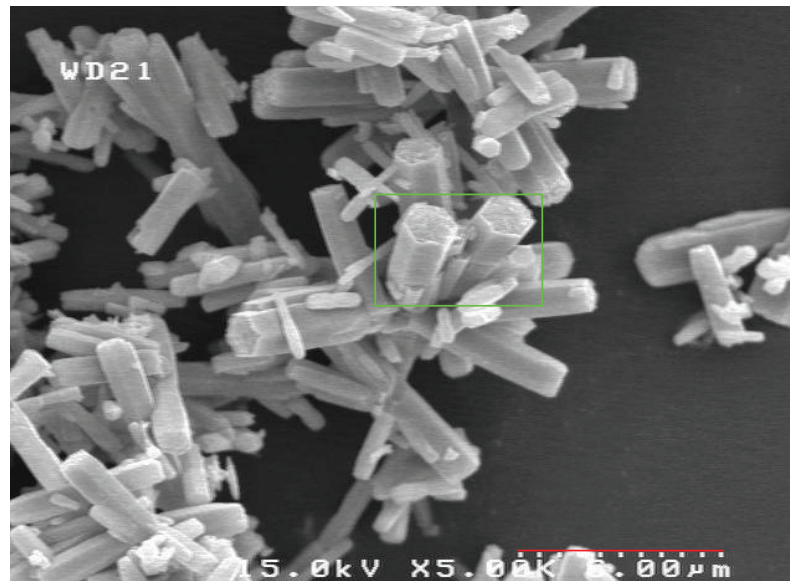

(d)

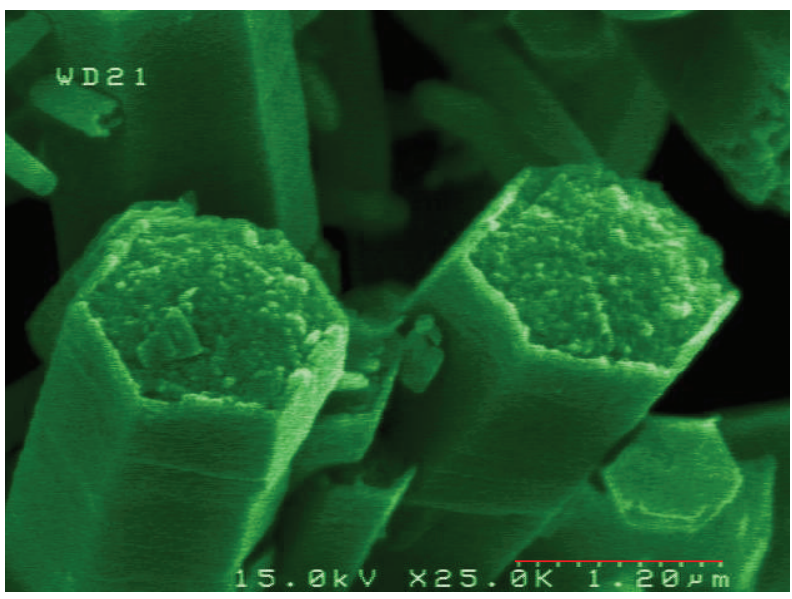

(e)

FIGURE 1: (a) XRD patterns for the prepared ZnO powder, (b) XRD pattern for the standard sample (JCPDS\#036-1451), (c) comparative graph, and (d-e) typical morphology of the $\mathrm{ZnO}$ powder.

TABLE 1: $d$-spacing and diffraction peak intensity of the single-phase FAp and FAp-ZnO composite nanopowders in comparison with the standard FAp (JCPDS\#15-0876).

\begin{tabular}{|c|c|c|c|c|c|c|c|c|}
\hline \multicolumn{3}{|c|}{$d$-Spacing $(\mathrm{nm})$} & \multicolumn{3}{|c|}{ Relative intensity (\%) } & \multirow{2}{*}{\multicolumn{3}{|c|}{$h \quad k \quad l$}} \\
\hline FAp & FAp-ZnO & JCPDS & FAp & FAp-ZnO & JCPDS & & & \\
\hline 0.34421 & 0.34430 & 0.34420 & 30.90 & 27.58 & 40 & $(0$ & 0 & 2) \\
\hline 0.28036 & 0.28028 & 0.28000 & 100.00 & 100.00 & 100 & $(2$ & 1 & 1) \\
\hline 0.27057 & 0.27074 & 0.27020 & 56.14 & 51.43 & 60 & $(3$ & 0 & 0) \\
\hline 0.19379 & 0.19379 & 0.19370 & 33.94 & 36.35 & 25 & $(2$ & 2 & 2) \\
\hline 0.18367 & 0.18376 & 0.18370 & 40.54 & 29.94 & 30 & $(2$ & 1 & 3) \\
\hline 0.17194 & 0.17196 & 0.17220 & 14.86 & 12.79 & 16 & $(0$ & 0 & 4) \\
\hline
\end{tabular}

process. Since interfacial reactions result in the formation of new phases, influence densification, mechanical properties and even degrade the biological properties of the composites [7], the obtained product is well preferred for functional applications. Figures 3(d) and 3(e) show the morphological features of FAp- $\mathrm{ZnO}$ composite nanopowders after $5 \mathrm{~h}$ of milling. These observations demonstrate that the experimental outcome was composed of both agglomerates and fine particles. A higher magnification of FE-SEM image indicates that the agglomerates included many smaller particles with 


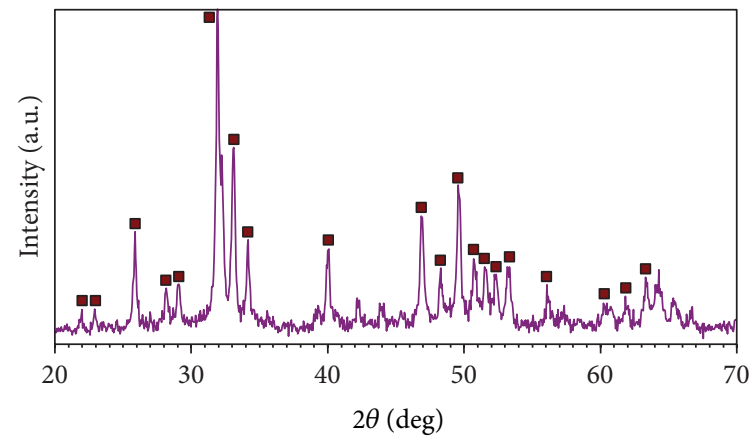

- FAp

(a)

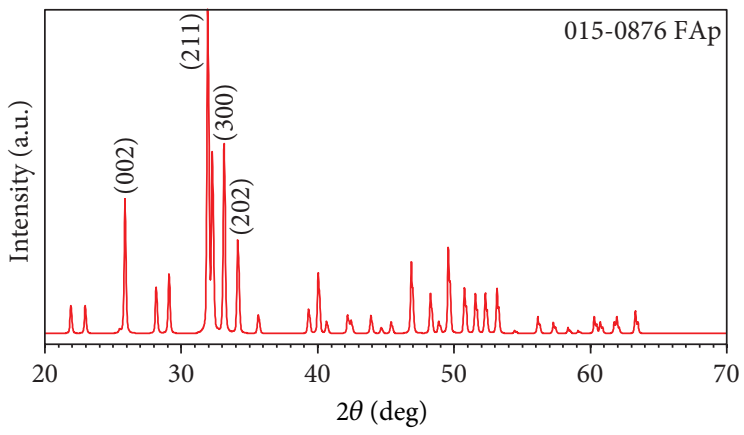

(b)

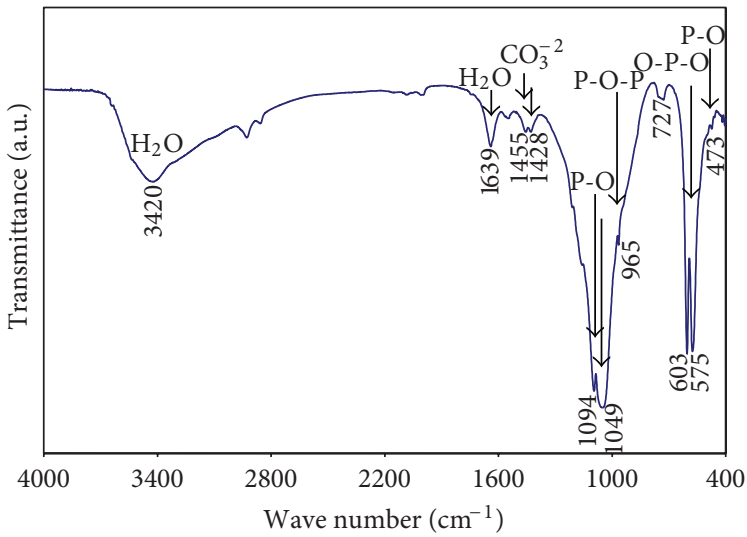

(c)

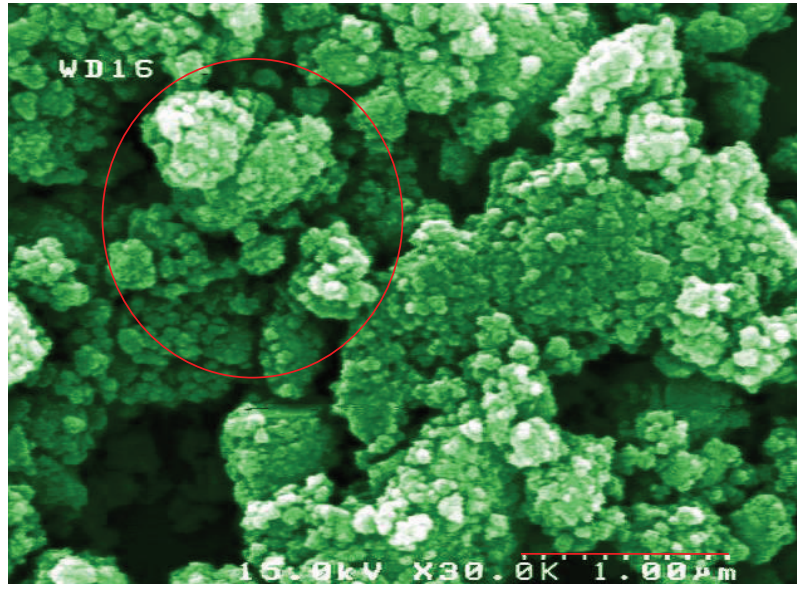

(d)

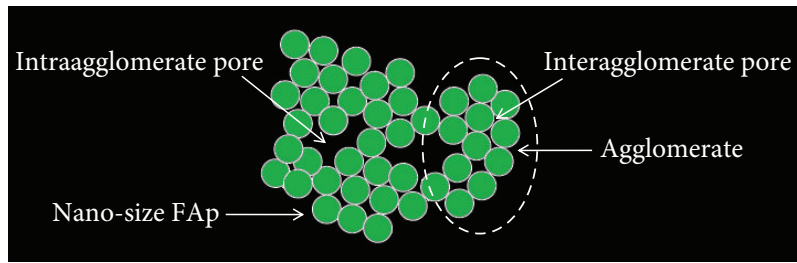

(e)

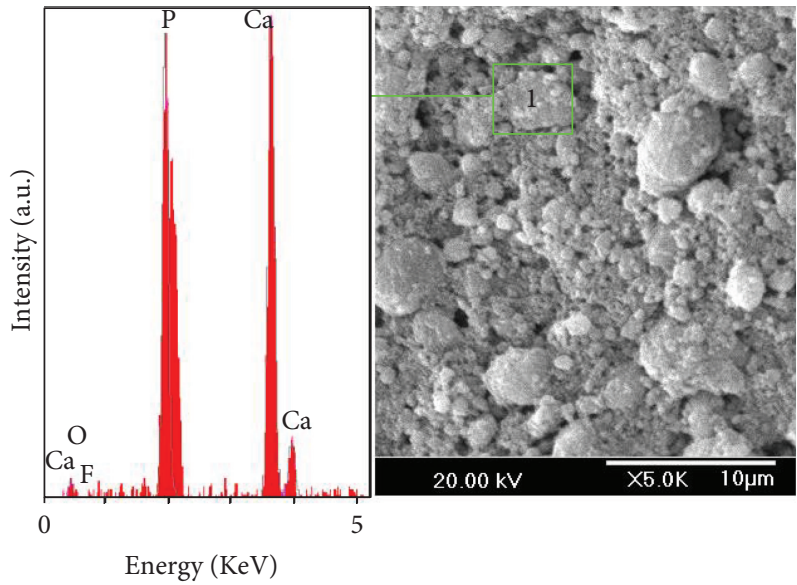

(f)

FIgure 2: (a) The XRD profile for the mixture of $\mathrm{CaO}, \mathrm{P}_{2} \mathrm{O}_{5}$, and $\mathrm{CaF}_{2}$ powders after mechanical activation for $5 \mathrm{~h}$ (b) XRD pattern of the standard sample (JCPDS\#15-0876), (c) FT-IR spectrum, (d) morphology and particle size distribution, (e) schematic picture of the morphological features, and (f) EDX spectra of the nanocrystalline FAp produced after $5 \mathrm{~h}$ of milling.

TABLE 2: Lattice parameters and their variations for single-phase FAp and FAp-ZnO composite nanopowders in comparison with the standard FAp (JCPDS\#15-0876).

\begin{tabular}{lcccccc}
\hline \multirow{2}{*}{ Sample } & & \multicolumn{4}{c}{ Lattice parameters } \\
& $a$-Axis $(\AA)$ & $c$-Axis $(\AA)$ & $V\left(\AA^{3}\right)$ & $\Delta a(\AA)$ & $\Delta c(\AA)$ & $\Delta V\left(\AA^{3}\right)$ \\
\hline FAp & 9.373 & 6.884 & 1565.778 & +0.005 & +1.514 \\
FAp-ZnO & 9.379 & 6.886 & 1568.239 & +0.011 & +0.002 & +3.975 \\
JCPDS & 9.368 & 6.884 & 1564.264 & - & - \\
\hline
\end{tabular}




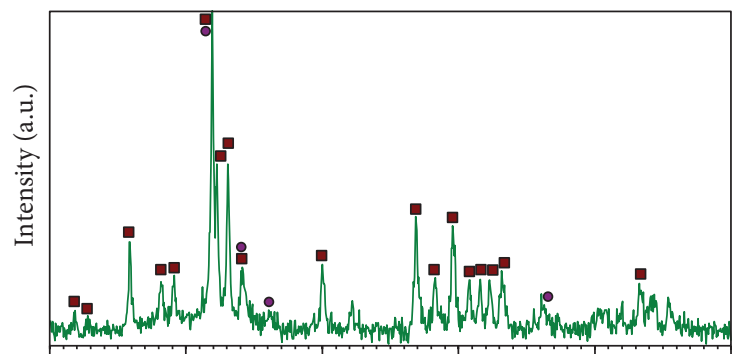

- FAp

- $\mathrm{ZnO}$

(a)
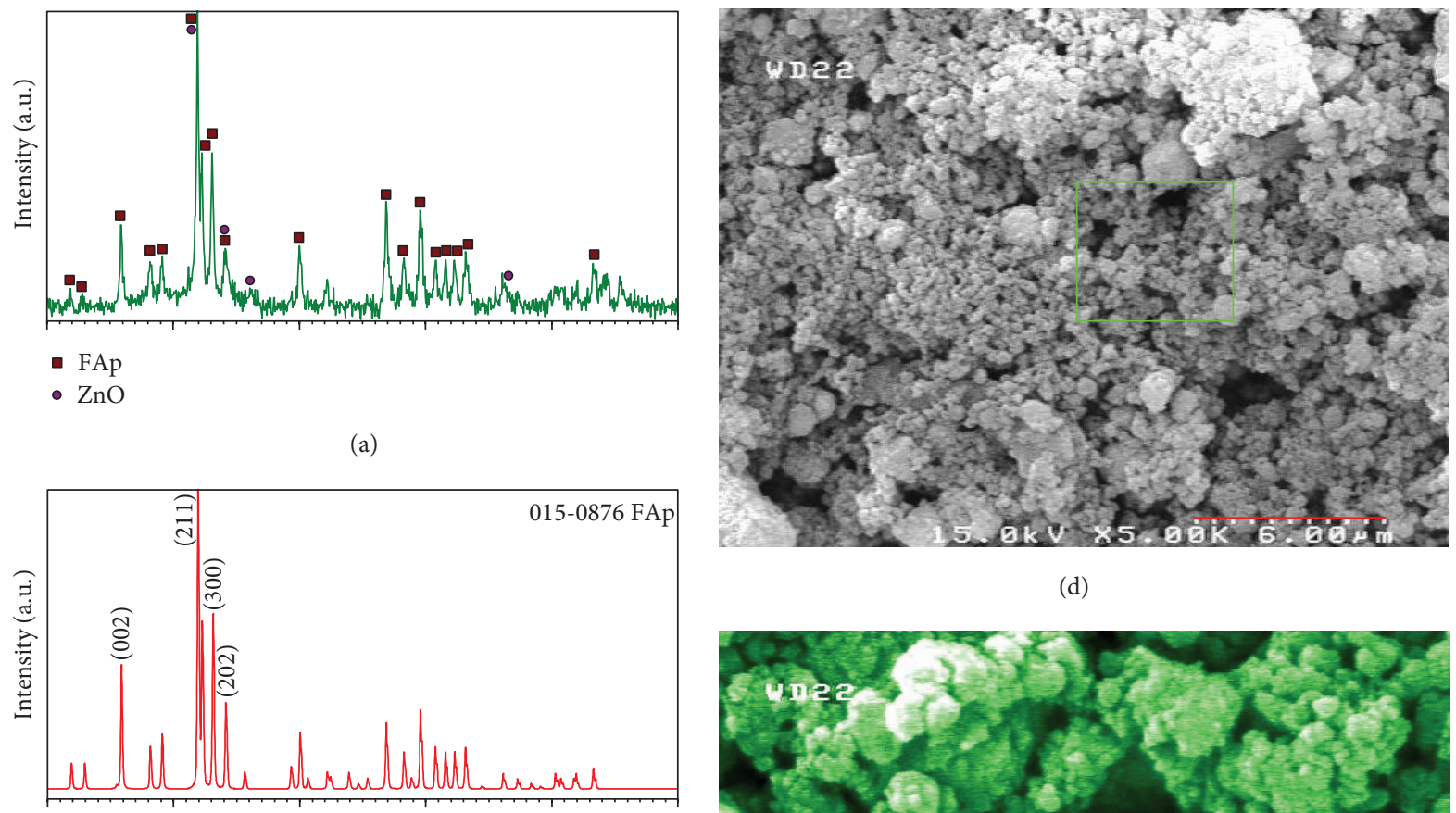

(d)

(b)
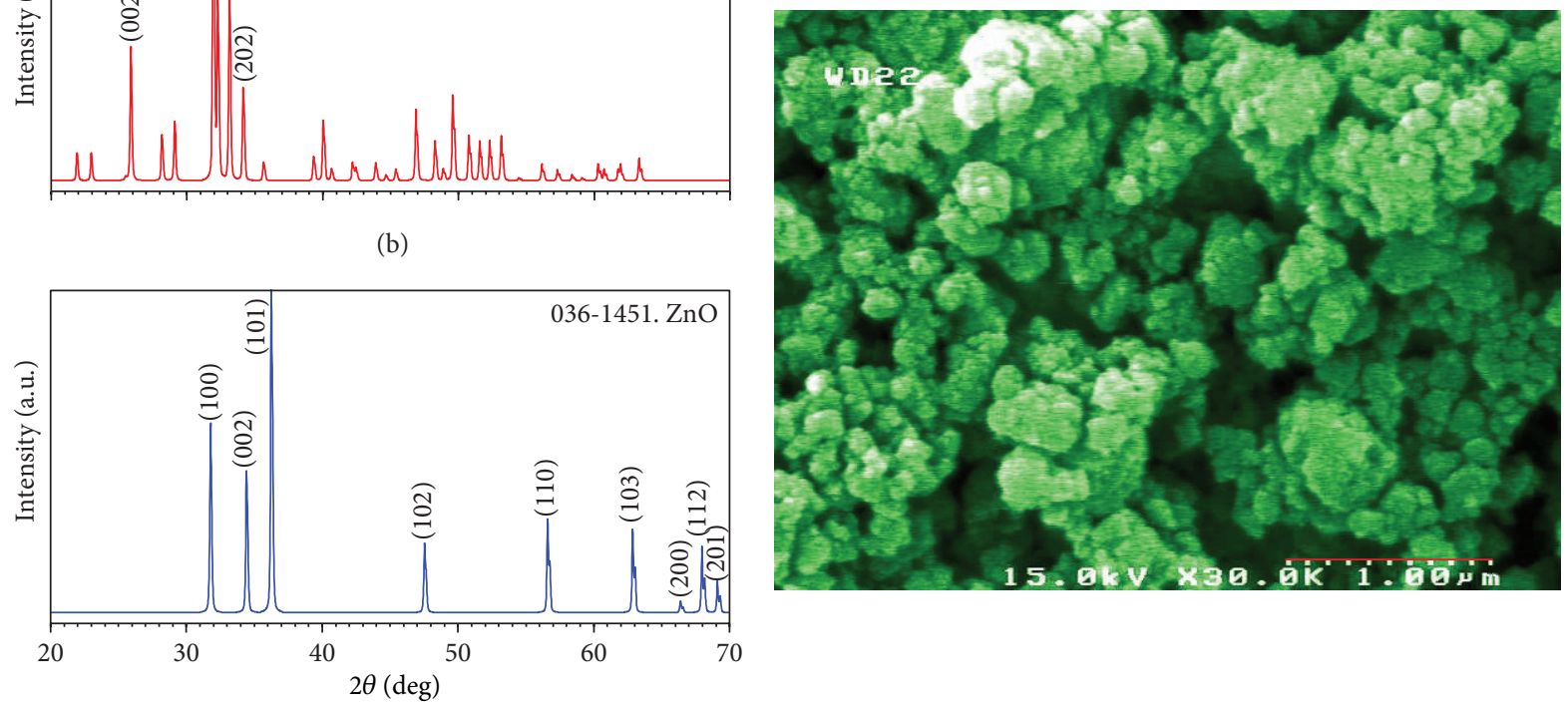

(c)

(e)

Figure 3: (a) XRD profile of $\mathrm{CaO}, \mathrm{P}_{2} \mathrm{O}_{5}$, and $\mathrm{CaF}_{2}$ powder mixture in the presence of $5 \mathrm{wt} . \% \mathrm{ZnO}$ after $5 \mathrm{~h}$ of milling, (b) XRD pattern of the standard sample (JCPDS\#15-0876), (c) XRD patterns of the standard ZnO (JCPDS\#036-1451), and (d-e) morphological features of FAp- $\mathrm{ZnO}$ composite nanopowders after $5 \mathrm{~h}$ of milling.

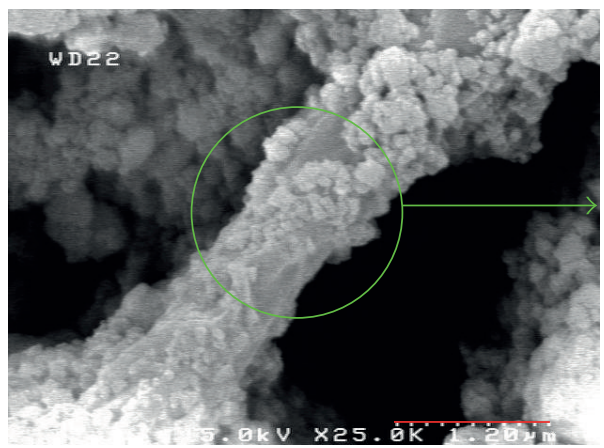

(a)

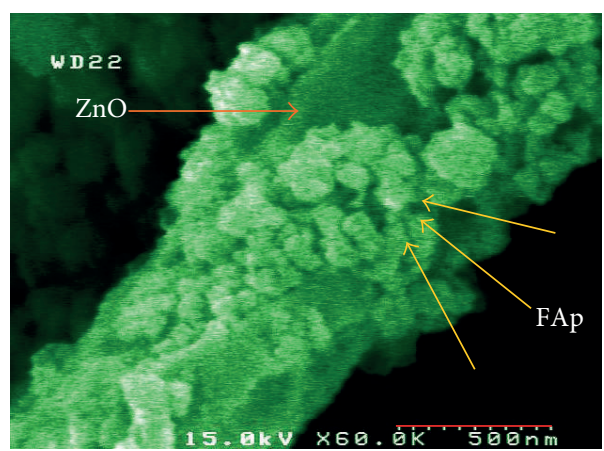

(b)

Figure 4: (a) Coated ZnO nano-rod-shape particle prepared after $5 \mathrm{~h}$ of milling, (b) higher magnification. 


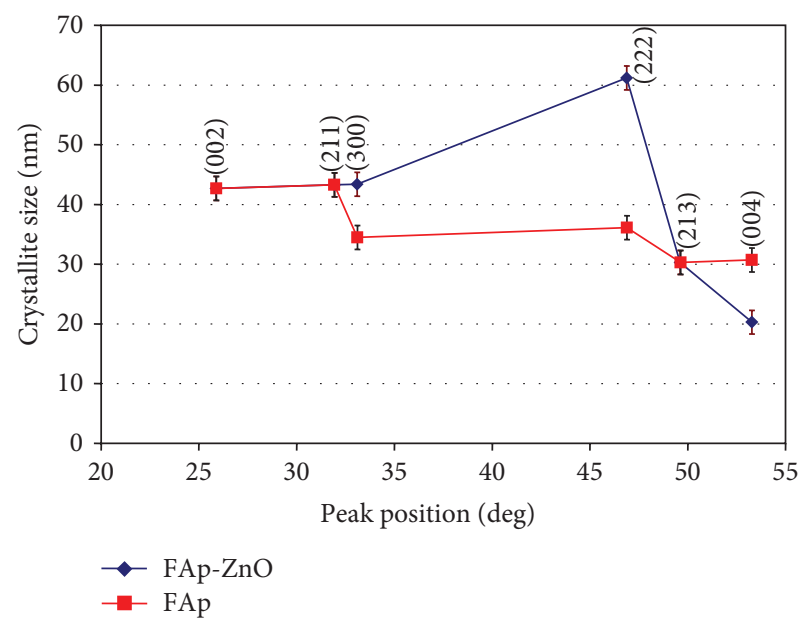

(a)

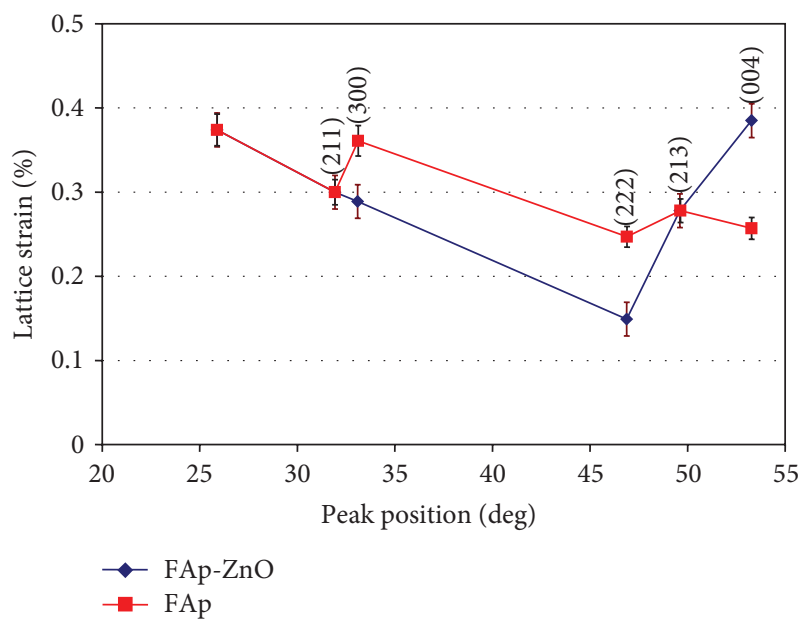

(c)

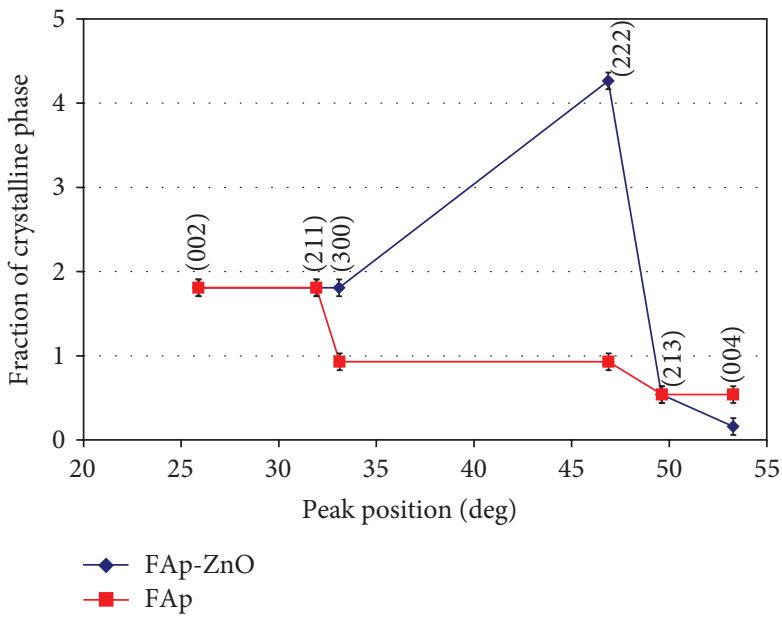

(e)

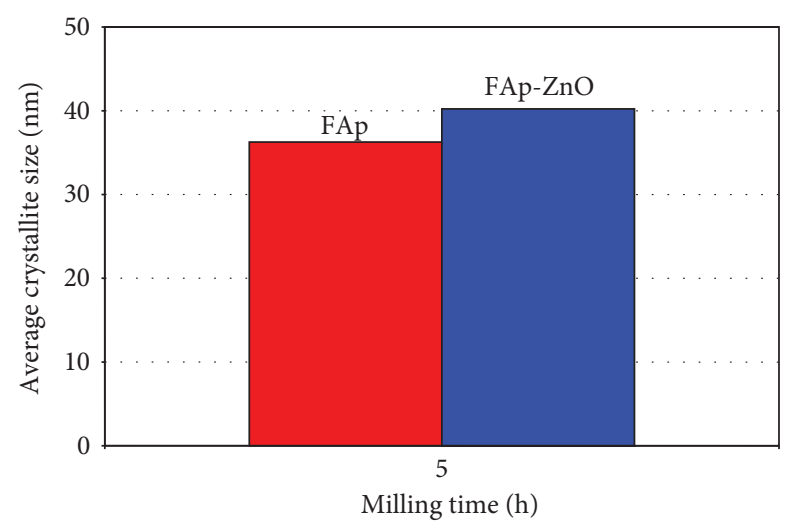

(b)

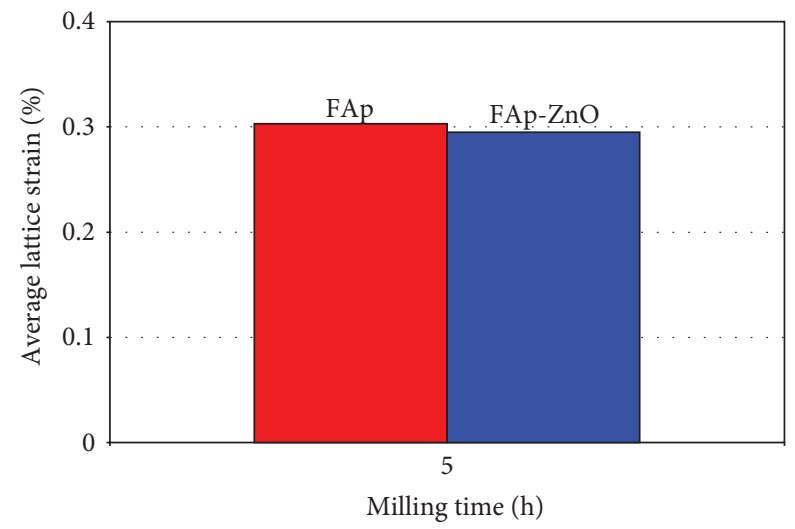

(d)

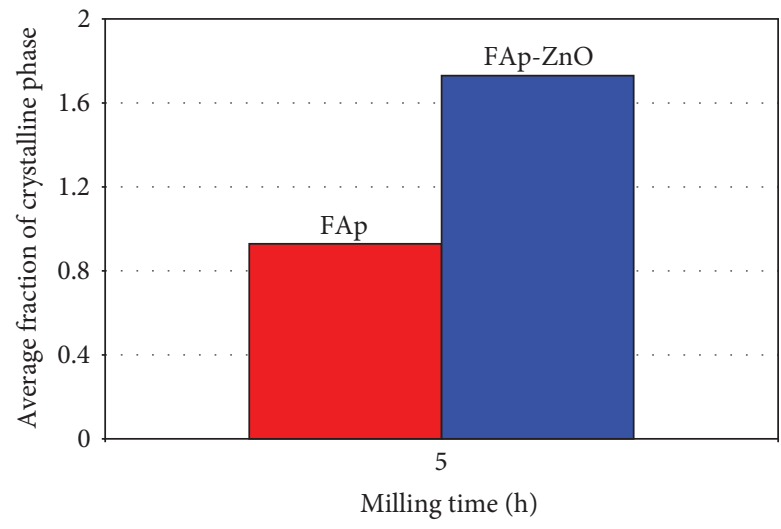

(f)

FIGURE 5: Change in the (a-b) crystallite size, (c-d) lattice strain, and (e-f) crystallinity as function of peak position after $5 \mathrm{~h}$ of milling. 
the average size of about $58 \mathrm{~nm}$ (Figure 3(e)). The intraagglomerate pore sizes, similar to nanocrystalline single phase FAp, were much smaller than the interagglomerate pore sizes.

Figure 4 shows the coated $\mathrm{ZnO}$ nano-rod-shape particle prepared during mechanochemical process. It can be seen that a heterogeneous coating and embedment of FAp fine particles $(58 \mathrm{~nm})$ onto the surface of $\mathrm{ZnO}$ nanorod shape particle was achieved by mechanochemical process after $5 \mathrm{~h}$. Hence, we reach to an important conclusion that using suitable conditions in mechanochemical process leads to the preparation of composite nanopowders with mechanically coated particles. This new approach to mechanosynthesis of bionanocomposites has the potential to revolutionize the field of biomaterials from dental cement powders to bone repair and augmentation $[21,22]$.

The $d$-spacing and diffraction peak intensity of the single-phase FAp and FAp- $\mathrm{ZnO}$ composite nanopowders were compared with the JCPDS standard corresponding to FAp (JCPDS\#15-0876) (Table 1). In accordance with Table 1, the calculated values are almost in agreement with standard values. Additionally, Table 1 shows that the ( $h k l=2 \quad 11$ ) peak intensity of FAp in the single-phase FAp and FAp-ZnO composite nanopowders maintained a given level $(100 \%)$ after $5 \mathrm{~h}$ of milling, which indicates that the FAp had a stable structure and confirms no interfacial reactions between FAp and $\mathrm{ZnO}$ occurred during mechanochemical process. Lattice parameters and their variations for the single-phase FAp and FAp-ZnO composite nanopowders are summarized in Table 2. According to data presented in Table 2, the $a$-axis values for FAp in the absence and presence of $\mathrm{ZnO}$ were similar to the reported values for standard FAp. Similarly, there were little changes observed in the $c$-axis. On the other hand, the determined amounts of unit cell volume of FAp demonstrate that milling up to $5 \mathrm{~h}$ was not accompanied by a remarkable change in unit cell volume. However, the minor changes in lattice parameters can probably be attributed to the lattice distortion of FAp during mechanical activation. However, the similarity of the values obtained in this paper to standard values provides further support for the purity of the samples that have been produced by the mechanochemical process.

Figure 5 shows the change in the crystallite size, lattice strain, and crystallinity as function of peak position and milling time. Using the (llll 00 2 $)$ plane (Figure 5(a)), when the FAp is synthesized alone, its crystallite size is around $43 \mathrm{~nm}$. In the presence of $5 \mathrm{wt} . \% \mathrm{ZnO}$, the crystallite size of FAp is equal to the previous sample $(43 \mathrm{~nm})$. This result was repeated for the samples using the $\left(\begin{array}{lll}2 & 1 & 1\end{array}\right)$ plane. For comparison, the mean values determined from the use of

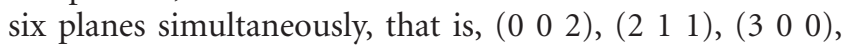
( $\left.\begin{array}{lll}2 & 2 & 2\end{array}\right),\left(\begin{array}{lll}2 & 1 & 3\end{array}\right)$, and ( $\left(\begin{array}{lll}0 & 0 & 4\end{array}\right)$ planes. The calculated data indicates that in the absence and presence of $5 \mathrm{wt} . \% \mathrm{ZnO}$ the average crystallite size of FAp was around 36 and $40 \mathrm{~nm}$, respectively (Figure 5(b)). The evaluation of the lattice strain of FAp reveals that in the presence of $5 \mathrm{wt} . \% \mathrm{ZnO}$ the lattice strain partially decreased from $0.303 \%$ to $0.295 \%$ after $5 \mathrm{~h}$ of milling (Figures 5(c) and 5(d)). A similar trend was observed in the crystallinity as was in the crystallite size, that is, an increase in the crystallinity in the presence of $5 \mathrm{wt} . \% \mathrm{ZnO}$
(Figures 5(e) and 5(f)). Based on these results, we conclude that the presence of $5 \mathrm{wt} . \% \mathrm{ZnO}$ was not accompanied by adverse effects on the structural features of the FAp during mechanochemical process.

\section{Conclusions}

The main result of this research is that the FAp-ZnO composite with high quality and appropriate structural and morphological features was successfully produced via novel and simple mechanochemical process. Crystallite size, lattice strain, and crystallinity in the absence and presence of $5 \mathrm{wt} . \% \mathrm{ZnO}$ were examined. In the presence of $5 \mathrm{wt} . \% \mathrm{ZnO}$ the product of mechanical activation was FAp-5 wt.\% ZnO composite nanopowders without any interfacial reactions and extra phases. The FE-SEM observations at higher magnification revealed that the experimental outcome had a cluster-like structure which consisted of several small particles with the average size of about $58 \mathrm{~nm}$. Moreover, in the presence of $\mathrm{ZnO}$ after $5 \mathrm{~h}$ of milling the mechanically coated particles were detected. The results suggest that the presence of $5 \mathrm{wt} . \% \mathrm{ZnO}$ is not only undesirable effects on the structural features but also can promote the morphological properties.

\section{Acknowledgment}

The authors are grateful to research affairs of Islamic Azad University, Najafabad Branch for supporting of this research.

\section{References}

[1] S. J. Kalita, A. Bhardwaj, and H. A. Bhatt, "Nanocrystalline calcium phosphate ceramics in biomedical engineering," Materials Science and Engineering C, vol. 27, no. 3, pp. 441449, 2007.

[2] H. W. Kim, L. H. Li, Y. H. Koh, J. C. Knowles, and H. E. Kim, "Sol-gel preparation and properties of fluoride-substituted hydroxyapatite powders," Journal of the American Ceramic Society, vol. 87, no. 10, pp. 1939-1944, 2004.

[3] M. H. Fathi and E. Mohammadi Zahrani, "Mechanical alloying synthesis and bioactivity evaluation of nanocrystalline fluoridated hydroxyapatite," Journal of Crystal Growth, vol. 311, no. 5, pp. 1392-1403, 2009.

[4] M. H. Fathi, E. Mohammadi Zahrani, and A. Zomorodian, "Novel fluorapatite/niobium composite coating for metallic human body implants," Materials Letters, vol. 63, no. 13-14, pp. 1195-1198, 2009.

[5] H. Zeng, K. K. Chittur, and W. R. Lacefield, "Analysis of bovine serum albumin adsorption on calcium phosphate and titanium surfaces," Biomaterials, vol. 20, no. 4, pp. 377-384, 1999.

[6] H. W. Kim, Y. M. Kong, C. J. Bae, Y. J. Noh, and H. E. Kim, "Sol-gel derived fluor-hydroxyapatite biocoatings on zirconia substrate," Biomaterials, vol. 25, no. 15, pp. 2919-2926, 2004.

[7] B. Viswanath and N. Ravishankar, "Interfacial reactions in hydroxyapatite/alumina nanocomposites," Scripta Materialia, vol. 55, no. 10, pp. 863-866, 2006.

[8] R. Ramachandra Rao and T. S. Kannan, "Synthesis and sintering of hydroxyapatite-zirconia composites," Materials Science and Engineering C, vol. 20, no. 1-2, pp. 187-193, 2002. 
[9] Z. Evis, "Reactions in hydroxylapatite-zirconia composites," Ceramics International, vol. 33, no. 6, pp. 987-991, 2007.

[10] S. Nath, R. Tripathi, and B. Basu, "Understanding phase stability, microstructure development and biocompatibility in calcium phosphate-titania composites, synthesized from hydroxyapatite and titanium powder mix," Materials Science and Engineering C, vol. 29, no. 1, pp. 97-107, 2009.

[11] E. Adolfsson, M. Nygren, and L. Hermansson, "Decomposition mechanisms in aluminum oxide-apatite systems," Journal of the American Ceramic Society, vol. 82, no. 10, pp. 2909-2912, 1999.

[12] H. W. Kim, Y. M. Kong, Y. H. Koh, H. E. Kim, H. M. Kim, and J. S. Ko, "Pressureless sintering and mechanical and biological properties of fluor-hydroxyapatite composites with zirconia," Journal of the American Ceramic Society, vol. 86, no. 12, pp. 2019-2026, 2003.

[13] F. Ben Ayed and J. Bouaziz, "Sintering of tricalcium phosphate-fluorapatite composites with zirconia," Journal of the European Ceramic Society, vol. 28, no. 10, pp. 1995-2002, 2008.

[14] I. Mobasherpour, M. Solati-Hashjin, A. Kazemzadeh, and M. Zakeri, "s," Journal of Alloys and Compounds, vol. 430, no. 1-2, pp. 330-333, 2007.

[15] N. Kivrak and A. C. Taş, "Synthesis of calcium hydroxyapatitetricalcium phosphate (HA-TCP) composite bioceramic powders and their sintering behavior," Journal of the American Ceramic Society, vol. 81, no. 9, pp. 2245-2252, 1998.

[16] F. Liu, F. Wang, T. Shimizu, K. Igarashi, and L. Zhao, "Hydroxyapatite formation on oxide films containing $\mathrm{Ca}$ and P by hydrothermal treatment," Ceramics International, vol. 32, no. 5, pp. 527-531, 2006.

[17] C. C. Silva, A. G. Pinheiro, M. A. R. Miranda, J. C. Góes, and A. S. B. Sombra, "Structural properties of hydroxyapatite obtained by mechanosynthesis," Solid State Sciences, vol. 5, no. 4, pp. 553-558, 2003.

[18] A. Balamurugan, S. Kannan, and S. Rajeswari, "Bioactive solgel hydroxyapatite surface for biomedical application-in vitro study," Trends in Biomaterials and Artificial Organs, vol. 16, no. 1, pp. 18-20, 2002.

[19] C. Suryanarayana, "Mechanical alloying and milling," Progress in Materials Science, vol. 46, no. 1-2, pp. 1-184, 2001.

[20] C. L. de Castro and B. S. Mitchell, "Nanoparticles from mechanical attrition," in Synthesis Functionalization and Surface Treatment of Nanoparticles, M. I. Baraton, Ed., pp. 1-14, American Scientific Publishers, Stevenson Ranch, Calif, USA, 2002.

[21] O. Gunduz, E. M. Erkan, S. Daglilar, S. Salman, S. Agathopoulos, and F. N. Oktar, "Composites of bovine hydroxyapatite (BHA) and ZnO," Journal of Materials Science, vol. 43, no. 8, pp. 2536-2540, 2008.

[22] A. Bandyopadhyay, E. A. Withey, J. Moore, and S. Bose, "Influence of $\mathrm{ZnO}$ doping in calcium phosphate ceramics," Materials Science and Engineering C, vol. 27, no. 1, pp. 14-17, 2007.

[23] R. Ebrahimi-Kahrizsangi, B. Nasiri-Tabrizi, and A. Chami, "Characterization of single-crystal fluorapatite nanoparticles synthesized via mechanochemical method," Particuology, vol. 9, no. 5, pp. 537-544, 2011.

[24] J. Qian, Y. Kang, W. Zhang, and Z. Li, "Fabrication, chemical composition change and phase evolution of biomorphic hydroxyapatite," Journal of Materials Science, vol. 19, no. 11, pp. 3373-3383, 2008.

[25] P. Singh, A. Kumar, A. Kaushal, D. Kaur, A. Pandey, and R. N. Goyal, "In situ high temperature XRD studies of
$\mathrm{ZnO}$ nanopowder prepared via cost effective ultrasonic mist chemical vapour deposition," Bulletin of Materials Science, vol. 31, no. 3, pp. 573-577, 2008.

[26] E. Landi, A. Tampieri, G. Celotti, and S. Sprio, "Densification behaviour and mechanisms of synthetic hydroxyapatites," Journal of the European Ceramic Society, vol. 20, no. 14-15, pp. 2377-2387, 2000.

[27] J. P. Lafon, E. Champion, and D. Bernache-Assollant, "Processing of AB-type carbonated hydroxyapatite $\mathrm{Ca}_{10-x}\left(\mathrm{PO}_{4}\right)_{6-x}\left(\mathrm{CO}_{3}\right)_{x}(\mathrm{OH})_{2-x-2 y}\left(\mathrm{CO}_{3}\right)_{y}$ ceramics with controlled composition," Journal of the European Ceramic Society, vol. 28, no. 1, pp. 139-147, 2008.

[28] I. Nikčević, V. Jokanović, M. Mitrić, Z. Nedić, D. Makovec, and D. Uskoković, "Mechanochemical synthesis of nanostructured fluorapatite/ fluorhydroxyapatite and carbonated fluorapatite/fluorhydroxyapatite," Journal of Solid State Chemistry, vol. 177, no. 7, pp. 2565-2574, 2004.

[29] A. Banerjee, A. Bandyopadhyay, and S. Bose, "Hydroxyapatite nanopowders: synthesis, densification and cell-materials interaction," Materials Science and Engineering C, vol. 27, no. 4, pp. 729-735, 2007.

[30] B. Basu and K. Balani, Advanced Structural Ceramics, The American Ceramic Society, Westerville, Ohio, USA; John Wiley \& Sons, Hoboken, NJ, USA, 1st edition, 2011.

[31] B. Nasiri-Tabrizi, P. Honarmandi, R. Ebrahimi-Kahrizsangi, and P. Honarmandi, "Synthesis of nanosize single-crystal hydroxyapatite via mechanochemical method," Materials Letters, vol. 63, no. 5, pp. 543-546, 2009.

[32] A. Fahami, R. Ebrahimi-Kahrizsangi, and B. Nasiri-Tabrizi, "Mechanochemical synthesis of hydroxyapatite/titanium nanocomposite," Solid State Sciences, vol. 13, no. 1, pp. 135-141, 2011.

[33] R. Ebrahimi-Kahrizsangi, B. Nasiri-Tabrizi, and A. Chami, "Synthesis and characterization of fluorapatite-titania (FAp$\mathrm{TiO}_{2}$ ) nanocomposite via mechanochemical process," Solid State Sciences, vol. 12, no. 9, pp. 1645-1651, 2010. 

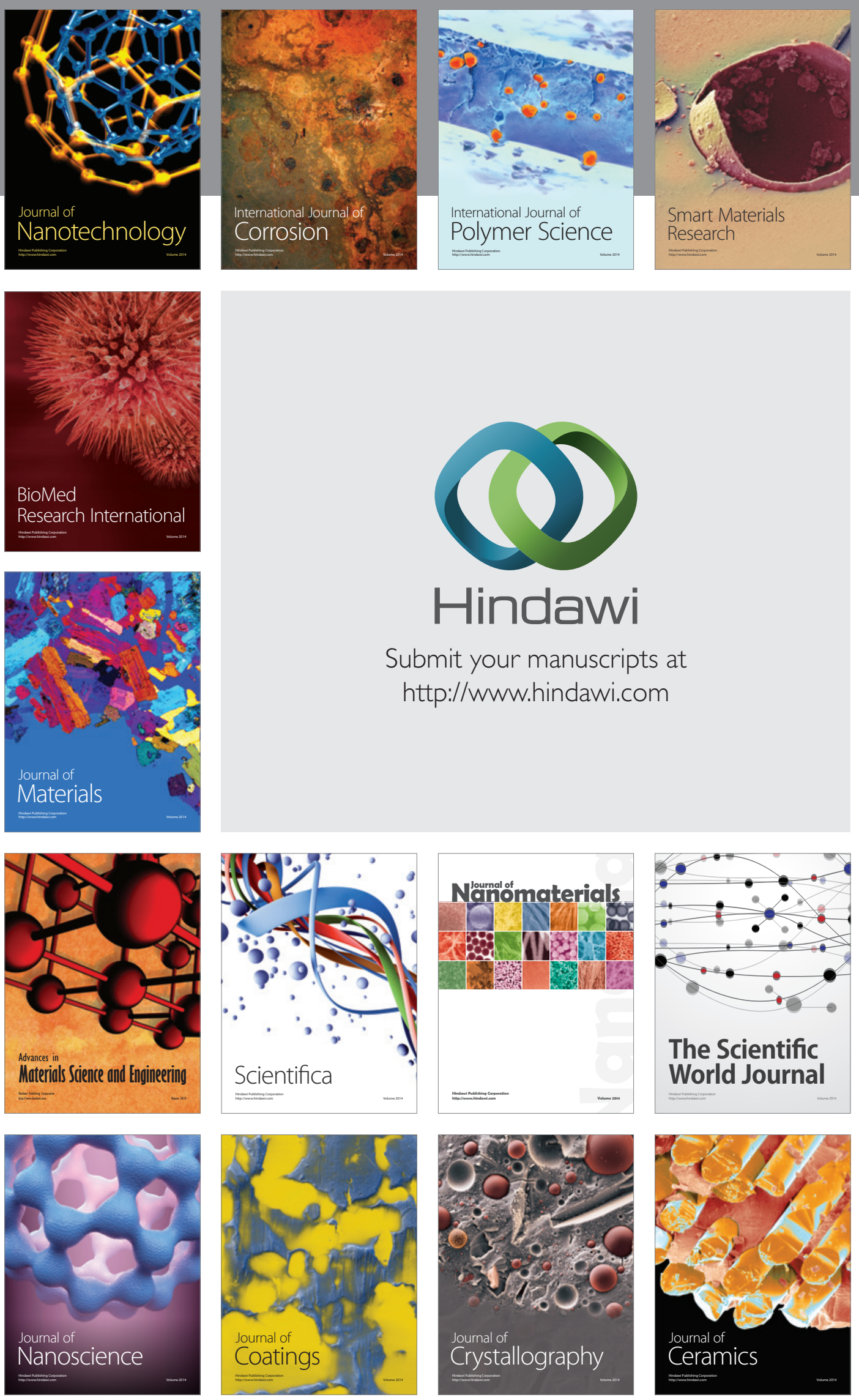

The Scientific World Journal

Submit your manuscripts at

http://www.hindawi.com

\section{World Journal}

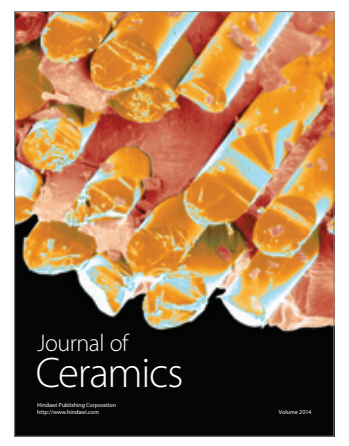

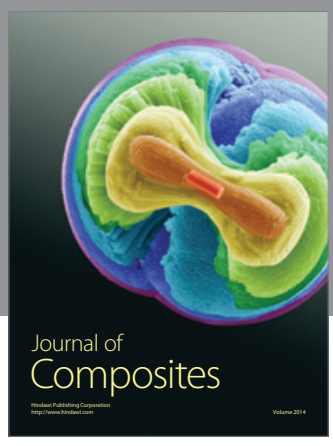
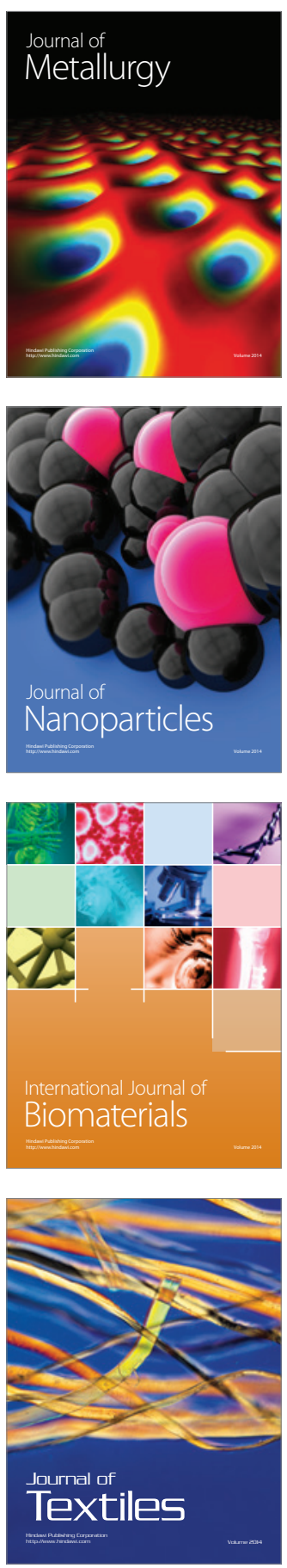